\title{
2006-2014 Estimation of Daqing Agricultural Labor Force Demand Based on the Mechanization Degree Model
}

\author{
Zhang Lin and Tian Yuan \\ Economics\&Management College of Heilongjiang Bayi Agricultural University \\ 52080063@qq.com
}

\begin{abstract}
In this paper, on the basis of the estimation on early agricultural labor demand, we constructed a method to estimate the agricultural labor demand based on the mechanization degree model. It proposed a linear relationship between the mechanization degree and agricultural labor demand in the short term from the micro perspective. We estimated 2006--2014 agricultural labor demand in Daqing city and analyzed the labor demand's impact from the mechanization degree and the planting structure. At last, we made the conclusion that the gross demand of agricultural labor continue to decrease, but the change in labor demand for different crops appears different characteristics.
\end{abstract}

Keywords: agriculture labor demand the mechanization degree

\section{Introduction}

Central "No.1 file" says that "we should actively develop modern agriculture" in 2007. Eighth session of the Fourth Plenary Session and the Fifth Plenary Session put forward clear requirements and milestones to the transformation of traditional agriculture and the achievement of agricultural modernization. Agricultural mechanization is an important component of agricultural modernization and it is one of the indicators to measure the agricultural modernization. Mechanization of agricultural machinery means replacing people and animal with machinery and equipment to engage in agricultural production process. In the stable case of supporting technical machinery level, the higher the degree of mechanization means the less demand for agricultural labor. Of course, there are many factors affecting the demand for agricultural labor. In this paper, we only explore and make a research on the relationship between the degree of agricultural mechanization and agricultural labor demand.

Agriculture refers to farming. Taking Daqing city in Heilongjiang Province as the sample, we are trying to draw some regularity conclusions on the basis of quantitative analysis of the relationship between the mechanization degree and agricultural labor demand.

\section{Literature Review}

There are some researches on the estimation on the agricultural labor demand. Nowadays, there are many mature and accessible methods. (1) Labor hour laws. He calculated the actual demand for agricultural labor according to the crop and the required man-hours of labor per acre (Cai Fang, 2007). Rockies (1997) improved this method to avoid the reliance on less reliable data of land-use area directly;(2) $\mathrm{He}$ calculated the actual demand for agricultural labor according to arable land per worker and then calculated surplus agricultural labor force (Guoxibao, 1995).The research group from agricultural department improved the method, which gave the reasonable amount of arable land required by worker in different areas combined with the structure of crops, irrigation and topography and other factors.according to the mechanization degree and 
cropping index over the country. According to the current size of arable land, a reasonable amount of labor demand has been given; (3) By the method of Cobb - Douglas production function, they calculated the amount of agricultural labor demand through analyzing C-D production function of two factors like labor and farmland and the derivative(National Bureau of Investigation Corps Agricultural Research Group, 2002); (4) The surplus agricultural labor force is calculated according to social average labor productivity. Agricultural labor demand = agricultural added value $\div(\mathrm{GDP} \div$ the number of social labor people)(Research Group of Agricultural Investigation Team in Sichuan, 2000); (5) The amount of labor required for agriculture means the amount of agricultural labor of obtaining maximumbenefitsfor the system(Liujianjin,1997; Wanghongling,1998); (6) International Comparative Law.He made judgments based on the share of the agricultural labor force accounted for the total labor force according to international standard of GDP per capital in some countries close to China(Wang jiangui, 2005); (7) He estimated the amount of agricultural surplus labor combined qualitative analysis with quantitative analysis(Zhong funing, 1995).(8) He regarded the average income of urban collective units manufacturing and wholesale and retail trade and restaurant industry as the reference value of rural labor input,agricultural surplus labor L1 $=\mathrm{L} \times \mathrm{R} 1, \mathrm{R} 1=(1-\mathrm{MR} 1 / \mathrm{MR} 2) \times 100 \%, \mathrm{~L} 1$ is the number of agricultural surplus labor force, $\mathrm{L}$ is the number of the agricultural labor force, $\mathrm{R} 1$ is the ratio of surplus agricultural labor force, MR1 is the marginal revenue for the agricultural labor force, MR2 is the marginal revenue of non-agricultural labor force (Hou fengyun,2004); (9) Human unit calculation(Chenjiyuan,1991), he estimated the amount of rural surplus labor through the introduction of population quality and the coefficient of gross agricultural machinery .

The research on agricultural mechanization and labor demand is as follows. The level of mechanization directly affects the amount of labor demand in crop farming, thereby affecting the amount of surplus labor force in rural areas. Some scholars qualitatively analyzed the relationship between rural surplus labor force and agricultural mechanization. They thought agricultural mechanization accelerated the transfer of rural surplus labor and the transfer of rural surplus labor force promoted the development ofagricultural mechanization(liqiuting, 2005).In another word, It is the motivation that the development of agricultural mechanization promotes the transfer of rural surplus labor force on the contrary, the transfer of rural surplus labor not only can bring considerable economic benefits but also promote the development of agricultural mechanization(Yuqingdong, 2007) and both are complementary, mutually reinforcing, developing together. The reason of agricultural mechanization promotes the transfer of agricultural labor force aimed at improving agricultural labor productivity, leading the development of secondary and tertiary industries and promoting the rural industrial structure adjustment(Huang yuxiang, Zhu ruixiang, 2005). Liu qingfeng and Liu jinlan (2006) selected the degree of agricultural mechanization as independent variables, the demand for agricultural labor as the dependent variable. In practice, they selected the size of the total power of agricultural machinery in current year in China as the degree of agricultural mechanization, and selected the agricultural labor force accounts for the proportion of China's total population as the dependent variable, then assuming a linear relationship between the two, estimating the extent of demand at different level of mechanization of the agricultural labor force with the method of least squares .Lou jiang and Zhu huajun(2006) estimated the relationship between elements of surplus rural labor force and the degree of agricultural mechanization, which builds a mathematical model considering some factors like the labor force, per capita land, technology and equipment on the theoretical basis of agricultural systems science .

In summary, the existing research on the demand for agricultural labor force lacked of revelation between the degree of agricultural mechanization and the amount relationship of labor force demand.This article from the micro perspective will establish agricultural 
labor demand model that estimates the changes of the amount of labor demand on the basis of the changes of degree of mechanization in order to enrich the estimation methods of agricultural labor demand and provide a basis for the formulation of agricultural development policies.

\section{The Estimation Method}

The main factors affecting the demand for labor force is arable land, production structure and the degree of mechanization. We selects the demand of agricultural labor force as the explained variable and selects arable area, crop types, the degree of mechanization as the explanatory variables in this model. Arable land that belongs to the area of actual sowing or transplanting crops adopts the index of snown area, including arable area planting crops on cultivated land area or on non-cultivated land area and the area re-replanted crops or replanted crops as a result of disasters. Production structure refers to the cultivation of different crops .Different crops have different labor force demands, such as rice needs more labor force with the expansion of the rice acreage and the demand of labor force will increase; Corn requires less labor input with the expansion of the corn creage and under the same circumstances of the total sown area, the total demand for labor force will be less. There are many indicators reflecting the level of mechanization. The index adopting in the article not only reflects the degree of substitution of agricultural machinery to the agricultural labor force in the actual production from the microscopic fully with the index of the degree of mechanization, but also effectively eliminates the problem of stock index of agricultural machinery in using efficiency and the use of supporting agricultural machinery.

\subsection{Basic Assumptions}

3.1.1 Assuming the effect is identical when the labor force is substituted with agricultural machinery in similar power .

3.1.2 Assuming keeping the technological level of agricultural machinery constant in a certain period, and then in the short time the changing of agricultural machinery technical level will not lead to the varying of labor substitution effect.

3.1.3 Assuming the labor force is homogeneous. Labor force in agricultural production affected by gender, age, education level and other factors, in order to simplify the model, we should make no difference in assumptions to the labor force temporarily.

\subsection{Model Building}

Demand for labor $=f($ level of mechanization, cultivated area, production structure $)$ Then:

$D L=f(x, s, i)$

In the formula:

$D L$ — the demand of labor force;

$s$-crop acreage;

$x$-level of mechanization, which refers to the ratio of mechanical work plantings account for total sown area;

$x=$ the area of mechanical work plantings/total sown area

$i$-crop species.

Under the same conditions, the substitution of the degree of mechanization for labor force is linear. If the substitution of one agricultural machinery for labor force is $\mathrm{K}$, and then the substituted labor force by two agricultural machinery is $2 \mathrm{~K}$; Under the condition 
of the planting area being determined, the degree of mechanization $\mathrm{m} \%$ means that $\mathrm{m} \%$ of the amount of work is done by machinery and $(1-\mathrm{m} \%)$ of the amount of work is done by people. The seasonal characteristics determines different demands of labor force in different segments of agricultural priduction, alternating agricultural busy and slack. To make sure the agricultural production in every step,designing parameters in the model selects the amount of labor demand in planting units on different degree of mechanization during the stage of peak production.

Estimation modelof labor demand of a crop:

$D L(x)=a s x+b s(1-x)$

Estimation modelof labor demand of many crops:

$$
D L\left(x_{i}\right)=\sum_{i}^{n}\left[a_{i} s_{i} x_{i}+b_{i} s_{i}\left(1-x_{i}\right)\right] \quad i=1,2,3 \cdots n \quad x \in[0,1]
$$

In the formula:

$a$ - the labor demand in every planting unit on the condition that the degree of mechanization is $100 \%$;

$b$ - the labor demand in every planting unit on the condition that the degree of mechanization is $0 \%$;

$n$ — varities of grown crops

The degree of mechanization of $0 \%$ means all jobs is completed by human and animal; mechanization of $100 \%$ means that all jobs is done by machinery.

$\mathrm{A}$ and $\mathrm{b}$ are parameters, whose economic significance can be described above, which may be obtained by the following steps:

If $x=1$, then the degree of mechanization is $100 \%$;

Then $D L\left(x_{i}\right)=a_{i} s_{i} x_{i}+b_{i} s i_{i}\left(1-x_{i}\right)$

$=a_{i} s_{i}$

$\therefore a_{i}=\frac{D L_{1}\left(x_{i}\right)}{s_{i}}$

$a$ is the labor demand per hectare when the degree of mechanization is $100 \%$;

Similarly, if $x=0$

$$
\begin{aligned}
& \text { 则 } D L\left(x_{i}\right)=a_{i} s_{i} x_{i}+b_{i} s_{i}\left(1-x_{i}\right) \\
& =b_{i} s_{i} \\
& \therefore b_{i}=\frac{D L_{1}\left(x_{i}\right)}{s_{i}}
\end{aligned}
$$

$b$ is the demand for labor force per hectare when the degree of mechanization is $0 \%$.

In order to obtain data directly from the actual survey, provided:

$$
A=\frac{1}{a}
$$

$A \_$affordable area per person on the condition that the degree of mechanization is $100 \%$; 
$B=\frac{1}{b}$

$B \_$affordable area per person on the condition that the degree of mechanization is $0 \%$.

Obtaining affordable area per person on the condition that the degree of mechanization is $100 \%$ and $0 \%$ in different regions for different crops. According to the above formula , it is clear that when the planting area is $S$, we can get the amount required labor force in planting different crops at any degree of mechanization.

The model through parameter's adjustment can be used to estimate the labor demand of the short-term and the long-term in different regions and it is with good adaptability. In the short time of keeping the agricultural machinery and technological equipment unchanged, the model can be used for estimating agricultural labor demand on different degrees of mechanization .A, B can be obtained through field surveys, and the survey data is affordable area per person on the condition that the degree of mechanization is $100 \%$ and $0 \%$ without employees in the busy time .

The method of estimating the peak demand of labor force will help protect agricultural production successfully completed. we can get the amount required labor force in planting different crops at any degree of mechanization according to the above formula. We can estimate agricultural labor demand according to adjustable parameters A, B, in different regions. In the long time, agricultural machinery power and technological level will continue to improve and affordable area per person keeps constant in the busy part on the condition that the degree of mechanization is $0 \%$ and parameters B keeps unchanged. Affordable area per person increases in the busy part on the condition that the degree of mechanization is $100 \%$ and parameters A will increase. Parameters' changes show that the relationship between the technology of machinery equipment and labor demand, which can be used to predict the improvement of technology of mechanical equipment to the demand of agricultural labor force with many programs. In addition, it has good flexibility.

\subsection{Data Sources}

Acreage area data originate from the "Daqing Statistical Yearbook" and "The second national agricultural census data of Daqing City,"; The information on the degree of crop mechanization originate from Daqing Agriculture Commission. The eatimation of model parameters (A, B) of agricultural labor demand on the basis of the degree of mechanization originates from the actual survey of five districts and four counties in Daqing City. Saertuqu district and Ranghulu district can be regarded as a work area, which are adjacent, working essentially in the same way, have similar geographical environment and have less arable land; Honggang district, Longfeng district are adjacent to Datong district with similar cultivative methods and mechanization, which can be regarded as a work area. The survey used the ways of questionnaires and interviews,in Zhaoyuan County, Zhaozhou, Lindian, Duerbote County, Datong district, Ranghulu district, a total of six districts adopt the way of questionnaires and interviews; The survey mainly prepares for rural male labor force who are above 40 years old, engaged in agricultural production for at least 15 years and experienced the mechanization of agricultural production process. As farmers in the actural production process hold different degrees of mechanization and hold large gaps. We should not only make typical investigations to large farmers similar to family farms, but also make universal investigations to general household in the selection of the survey sample, which can be regarded as a representative of the degree of mechanization. Among the estimation of rural labor demand, to the extent that most of the existing mechanized farmers calculated on the basis, to the extent that the degree of mechanization of typical farmers calculated 
as a reference.

\section{Empirical Analysis}

\subsection{Establishing the Estimation Model of Agricultural Labor Demand in Daqing City}

Through surveys and interviews, according to formula (3) we should establish the labor demand model of Daqing city based on the degree of mechanization, and estimation model of different crops as follows:

$$
\begin{aligned}
& D L_{1}=a s x+b s(1-x)=\frac{1}{7} s x+\frac{1}{1} s(1-x) \\
& D L_{2}=a s x+b s(1-x)=\frac{1}{10} s x+\frac{1}{2} s(1-x) \\
& D L_{3}=a s x+b s(1-x)=\frac{1}{10} s x+\frac{1}{2} s(1-x) \\
& D L_{4}=a s x+b s(1-x)=\frac{1}{8} s x+\frac{1}{2} s(1-x) \\
& D L_{5}=a s x+b s(1-x)=\frac{1}{4} s x+\frac{1}{1} s(1-x) \\
& D L_{6}=a s x+b s(1-x)=\frac{1}{2} s x+\frac{1}{0.5} s(1-x) \\
& D L_{7}=a s x+b s(1-x)=\frac{1}{6} s x+\frac{1}{2} s(1-x) \\
& D L_{8}=a s x+b s(1-x)=\frac{1}{6} s x+\frac{1}{1} s(1-x)
\end{aligned}
$$

Among them:

1-Rice; 2-Wheat; 3-Corn; 4-Beans; 5-Commercial Crops

6 -Vegetables and Melons 7-Freed Crops 8- Else Grain Crops

In the process of planting crops, the degree of mechanization includes tractor mechanization, sowing mechanization, harvesting mechanization of the three production steps. Sowing mechanization and harvesting mechanization hold higher demands to

\begin{tabular}{|c|c|c|c|c|c|c|c|c|c|}
\hline Year & otal & Rice & Wheat & Corn & Beans & $\begin{array}{l}\text { Economic } \\
\text { crops }\end{array}$ & $\begin{array}{l}\text { Vegetables } \\
\text { and melons }\end{array}$ & $\begin{array}{l}\text { Forage } \\
\text { crops }\end{array}$ & Other \\
\hline 2006 & 269685 & 22040 & 117 & 84802 & 10983 & 38810 & 67834 & 16379 & 28720 \\
\hline 2007 & 275455 & 25394 & 113 & 84624 & 11444 & 40064 & 74605 & 15512 & 23700 \\
\hline 2008 & 274989 & 21910 & 222 & 66445 & 11180 & 37197 & 77554 & 15903 & 44578 \\
\hline 2009 & 258772 & 23695 & 146 & 110342 & 9935 & 25039 & 51330 & 8831 & 29454 \\
\hline 2010 & 217895 & 25586 & 38 & 95110 & 9688 & 18536 & 43062 & 4466 & 21410 \\
\hline
\end{tabular}
farming season. We use the weighted average value of the three aspects of mechanization in estimating the final index on the degree of mechanization of labor demand.

\subsection{Estimation Results}

Based on the degree of mechanization, we can estimate the amount of agricultural labor demand of Daqing city combined with planting area of different crops (Table 1).

Table 1. 2006--2014 Agricultural Labor Demands in Daqing City Unit: Person 


\begin{tabular}{lllrllllll}
2011 & 221548 & 26778 & 39 & 80192 & 6765 & 21526 & 62335 & 3595 & 20318 \\
2012 & 216366 & 30732 & 42 & 75848 & 6470 & 20779 & 58220 & 2919 & 21358 \\
2013 & 205335 & 35015 & 203 & 66784 & 5147 & 16752 & 62857 & 2318 & 16259 \\
2014 & 194992 & 35231 & 222 & 67337 & 4206 & 13844 & 56054 & 2140 & 15958 \\
\hline
\end{tabular}

\subsection{Result Analysis}

4.3.1. The Total Agricultural Labor Demand in Daqing City decreased Year by Year: From 2006 to 2014, the demand of agricultural labor force decreased by more than 7.47 million, which decreased $27.7 \%$ than 2006(Table1).

4.3.2. The Increasing of Sown Area Has Not Led to the Growth of Agricultural Labor Demand of Daqing City and the Planting Structure is the Main Factor in Affecting the Labor Demand Changes of Different Crops: From 2006 to 2014 the total sown area of Daqing city has increased by 124,200 hectares on $\mathrm{T}$ able 2, which increased by $19.61 \%$ than 2006 . The growth rate of sown area is far lower than the rate of decreasing in labor demand.

Table 2. 2006-2014 Sown Area of Crop in Daqing Unit: Hectare

\begin{tabular}{lllllllllll}
\hline $\begin{array}{l}\text { Year } \\
\text { Totalsown } \\
\text { area }\end{array}$ & \multicolumn{1}{c}{ Rice } & \multicolumn{2}{c}{ Wheat corn } & beans $\begin{array}{l}\text { Economic } \\
\text { crops }\end{array}$ & \multicolumn{2}{l}{$\begin{array}{l}\text { Vegetables Forage } \\
\text { and melonscrops }\end{array}$} & other \\
\hline 2006 & 633234 & 38991 & 988 & 347700 & 56267 & 50078 & 43764 & 57153 & 38293 \\
2007 & 634121 & 52466 & 1037 & 336648 & 59566 & 51695 & 48132 & 52977 & 31600 \\
2008 & 634134 & 55368 & 2047 & 290933 & 70206 & 47996 & 50035 & 58112 & 59437 \\
2009 & 693526 & 58896 & 1400 & 436134 & 62377 & 32309 & 33116 & 30022 & 39272 \\
2010 & 724415 & 64714 & 381 & 495983 & 64724 & 23917 & 27782 & 18368 & 28546 \\
2011 & 733510 & 70528 & 387 & 504096 & 46765 & 27776 & 40216 & 16651 & 27091 \\
2012 & 751418 & 84448 & 421 & 513736 & 45821 & 26811 & 37561 & 14143 & 28477 \\
2013 & 751106 & 98610 & 2033 & 517702 & 36766 & 21615 & 40553 & 12148 & 21679 \\
2014 & 757398 & 103673 & 2217 & 534082 & 30761 & 17863 & 36164 & 11361 & 21277 \\
\hline
\end{tabular}

During the time of 9 years, significant changes of planting structure occurred in Daqing City. The proportion of corn acreage accounting for the total sown area increased from $54.91 \%$ (Figure 1) to $70.52 \%$ (Figure 2) and the proportion of rice acreage accounting for the total sown area increased from $6.1 \%$ to $19.69 \%$. The sown area of two crops reached $84.21 \%$ in 2014 . The ratio of sown area of other crops continute to decrease, which reduced in 2006 from $38.93 \%$ to $15.79 \%$ in 2014 (Figure 1). The first reason is that the price of rice and wheat are high and the economic profits are well. The second reason is that the higher degree of mechanization not only can reduce labor demand and can effective be alternative to human, but also it enables labor to engage in other job. Thirdly, supporting technology is mature and anti-risk ability is strong. The economic crops and vegetables'market risk is large, which requires a large amount of labor force. In addition, the ratio of crops'sown area accounting for total sown area decreased obviously. As the planting ratio of corns and rice increased absolutely and the degree of mechanization continutes to increase, which lead to the growth of the agricultural sown area and the decreasing of labor demand. 


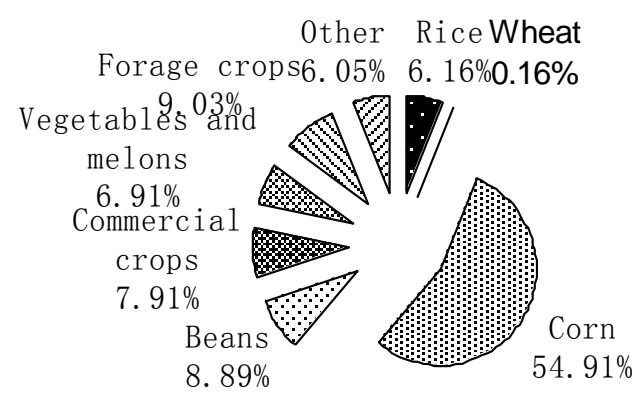

Figure 1. Planting Structure in 2006

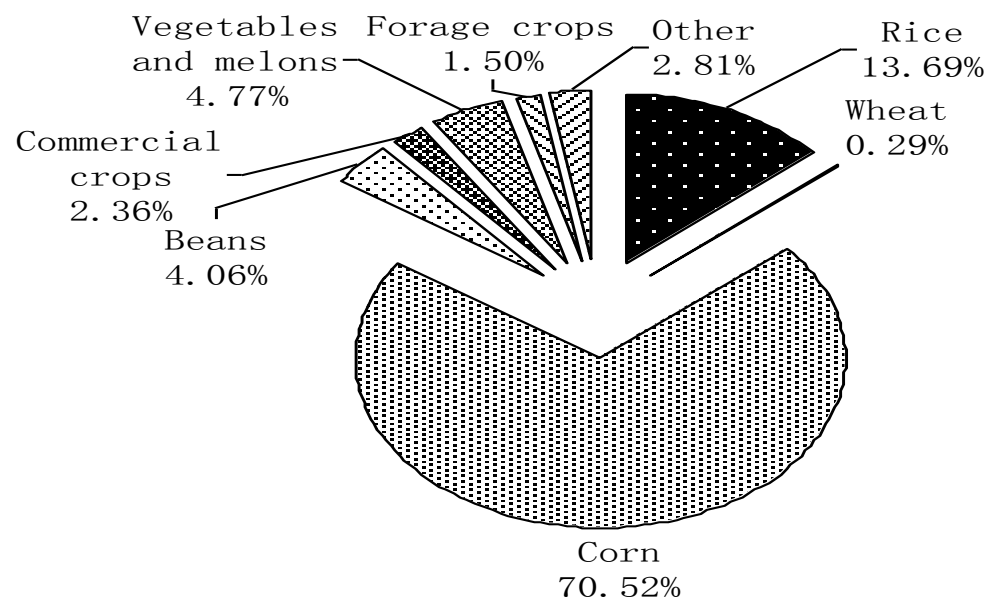

Figure 2. Planting Structure in 2014

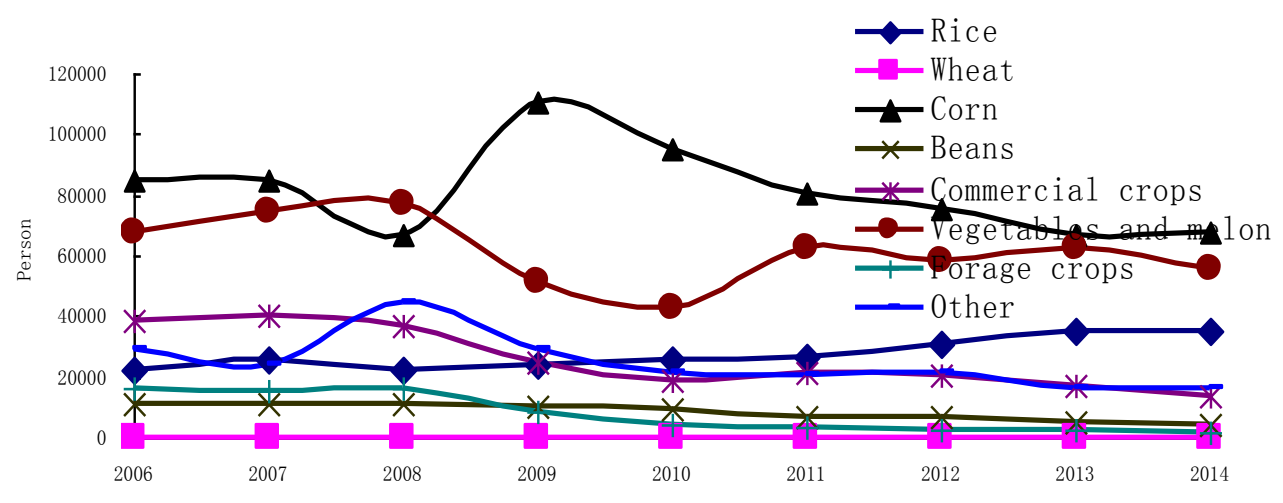

Figure 3. Labor Demand of Different Crops in Daqing City from 2006 to 2014

4.3.3. The Characteristics of the Labor Demand Change in Different Crops are Quite Different: Some crops are decreasing the demand for labor, which includes 
beans,economic crops,forage crops and other crops and which is similar to the total changing trend of agricultural labor force in Daqing; Labor demand for corn drastically rised in 2009, which increased of $66.07 \%$ compared with 2008. The reason is that the sown area in 2009 increased by $43.03 \%$ than 2008 and the degree of harvesting mechanization of corns was lower at that time; The changing of labor demand of economic crops, vegetables and melons fluctuated periodically, which caused the phased changing of sown area as a result of the instability of prices.Other crops also have this characteristic. And such crops are in the low level of mechanization, sown area is influenced by the demand for labor force; the labor demand of rice is increasing.

4.3.4. The Increasing of the Mechanization Degree Has a Significant Effect on Reducing the Demand for Labor Force: The mechanization degree of rice, wheat, corn, beans and feed products improved faster, among which the degree of mechanization of wheat, corn, beans, feed reached 90\%; Although the level of mechanization of rice is lower than the first three, it increased rapidly. On the one hand, machinery has an absolute advantage compared with human and animal and it can improve efficiency and reduce labor intensity; On the other hand, field crops with large scale cultivation can form the market of agricultural machinery service, thereby improving the overall level of mechanization. In contrast, economic crops and vegetables not only keep lower degree of mechanization, but also increase slowly.

\section{Conclusions}

5.1 We abstract the alternative relationship between agricultural labor force and agricultural machinery equipment with the method of estimation of agricultural labor demand on the basis of the degree of mechanization.It is possibe to estimate the agricultural labor demand effectively in restructuring through revealing some laws between the degree of mechanization and the agricultural labor demand.

5.2 The demand of agricultural labor force will decrease year by year. The total sown area increased and planting structure was further readjusted from 2006 to 2014. With the improvement of the degree of mechanization of corn, rice and main crops, agricultural demand for labor force continued to decline.

5.3 Changes in labor demand of different crops showed different characteristics. A general decline in the labor demand for field crops and the changing of labor demand of economic crops, vegetables and melons fluctuated periodically.

5.4 The degree of mechanization of economic crops, vegetables and melons needs to be improved.With the improvement of people's living standards, the demand for cash crops, vegetables and melons increase and the planting structure will be adjusted.Therefore, we should invent some machineries that applies to the management of crops, vegetables and melons and mechanical harvesting, which can reduce labor demands.

Further research is that through the degree of mechanization estimating the model of agricultural labor demand reflects the links between the industrial sector and the agricultural sector. We will make further study on the needs of the agricultural labor force in the framework of a unified market and interaction between the degree of agricultural mechanization and agricultural labor demand with the process of the industrialization .

\section{Acknowledgments}

This study was funded by science and technology issues HNK12A-14-13 of Heilongjiang Land Reclamation Bureau. 


\section{References}

[1] C. Fang, "Cracking the mystery of the rural surplus labor",.Chinese Journal of Population Science, vol. 2, (2007), pp. 2-7.

[2] P. Thomas and M. Robert, "On the study of agricultural labor force in China", China Rural Survey, vol. 4, (1997), pp. 28-39.

[3] G. Xibao, "Agricultural Surplus Labor and its transfer: Theoretical Considerations and the experience of China”, World Economy, vol. 12, (2002), pp. 25-32.

[4] L. Jianjin, "A empirical study on a farmer labor model and agricultural surplus labor", Chinese rural economy, vol. 6, (1997), pp. 15-22.

[5] W. Hongling, "A method of estimating the number of surplus agricultural labor", Statistical Research vol. 1, (1998), pp. 48-50.

[6] W. Jiangui, "The number of Chinese agricultural surplus labor", Chinese Social Science, vol. 5, (2005), pp. 27-35.

[7] Z. Funing, "Estimation of the number of rural surplus labor", Issues in Agricultural Economy, vol. 9, (1995), pp. 18-19.

[8] H. Fengyun, "The empirical analysis of the estimation of China's rural surplus labor and factors influencing the outflows scale", Chinese Rural Economy, vol. 3, (2004), pp. 13-21.

[9] C. Jiyuan, "Chinese Agricultural Surplus Labor Transfer - the way of farming modernized", Beijing: Economic Management Press, (1991), pp. 13-15.

[10] L. Qiuting, "Analyzing the problems of Kaifeng agricultural mechanization and the rural surplus labor transfer", [J] Chinese Agricultural Mechanization, vol. 5, (2005), pp. 30-31.

[11] H. Yuxiang and Z. Ruixiang, "Agricultural Mechanization and Rural Labor Force", Agricultural Mechanization Research, vol. 2, (2005), pp. 7-10.

[12] L. Qingfeng and L. Jinlan, "Based on the substitution effect of prediction model, eatablishing the demands of agricultural labor", Chinese Agricultural Mechanization, vol. 1, (2006), pp. 41-43.

[13] Z. Huajun and H. Lujia, "Correlation analysis of agricultural labor transfer and agricultural mechanization", Agricultural Systems Science and Comprehensive Study, vol. 22, vol. 1, (2006), pp. 66-69.

[14] J. M. Xiaohe, “The number of China's rural surplus labor", Chinese Rural Economy, vol. 12, (2007), pp. 4-9.

[15] A. Bhattacharyya and E. Parker, "Labor Productivity and Migration in Chinese Agriculture: AStochastic Frontier Approach.China Economic Review, vol. 10, (1999), pp. 59-74.

[16] C. Carter, Z. Funing and C. Fang, "China's Ongoing Reform of Agriculture”, San Francisc 1990 Institute, (1996). 